\title{
Obsolescência da função do intelectual na modernidade
}

\author{
ROBERVAL DE JESUS LEONE DOS SANTOS
}

\section{O intelectual}

$\mathrm{O}$ MUNDO, nas últimas décadas, vem sofrendo inúmeras transformações, nem todas imprevisíveis, decorrentes de ajustes econômicos e políticos sobre a estrutura capitalista, que vem se consolidando como uma realidade aparentemente rígida ao rompimento. Nesse conjunto de transformações, a atuação e a função do intelectual parecem impor a necessidade de uma discussão: é chegado o tempo de uma auto-reflexão.

A auto-reflexão, que neste texto se tenta iniciar, poderia começar com tributos ao Manifeste des intellectuels (1898) ou ao éthos que Fichte planejou instituir junto aos eruditos mediante seus antológicos ensinamentos constantes de Einige Vorlesungen über die Bestimmung des Gelehrten (1794), mas ver-se-ia logo o quanto inútil seria tal empreendimento se, já de início, não se admitisse a hipótese de que a ação efetiva dos intelectuais, desde essas primeiras autoreflexões, tem mudado em demasia para juntá-las a qualquer ponto de partida. Essa auto-reflexão, pois, tem de ser de um tipo novo.

Além disso, o escopo da discussão deve ser muito bem recortado em relação à base que vem condicionando as mudanças, obviamente o modo de produção capitalista.

Restringindo, pois, a presente análise às formações sociais capitalistas (1), existem algumas condições que devem ser discutidas ao se escrever isoladamente sobre o intelectual, antes de discutir a sua função, objeto principal do autor neste artigo.

Vejo, inicialmente, três condições:

\section{Condição 1: não reposição nem geração de valor}

Estando desvinculado do processo produtivo de mercadorias, o intelectual, em geral, necessita de um aporte pecuniário ou de recursos materiais diretos ou indiretos (2) derivados da mais-valia gerada na sociedade. Esse fato não se explica apenas por questões relacionadas com a classe a que possa pertencer e nem deve, embora seja tentador, ser tomado como uma parasitose ou um privilégio per se, mas sim como a maneira mais eficiente, pela divisão do trabalho, mediante a qual o indivíduo pode dispor de dois elementos que lhe são essen- 
ciais: a reflexão, que consome tempo, e o conhecimento, que consome informações, e tanto informações quanto tempo são mensuráveis em termos monetários e muito úteis no processo produtivo, isto é, no trabalho socialmente definido.

No interior do processo produtivo capitalista, haveria sérias dificuldades de uso de ambos os elementos para o mesmo resultado que se espera de um intelectual, isto é, produção de conceitos e de predições, uma vez que estaria em contradição com a reposição e a criação de valor (3), que repousam no fato de o tempo de trabalho dever ser alocado no produto e a informação a ele agregada estar desvinculada de quem lhe fez a síntese.

Não obstante, a condição não é necessária, pois, como adverte Marx, "O proletário intelectual de Leipzig [Milton, autor do Paraiso perdido], que sob a direção da editora produz livros (por exemplo, compêndios de economia), é um trabalhador produtivo; pois, desde o começo, seu produto se submete ao capital e só para acrescer o valor deste vem à luz" (Marx, 1987, v.1: 339).

Tal caso é pouco freqüente, porque da natureza da divisão do trabalho deriva a dificuldade da reprodutibilidade deste tipo de mão de obra, uma vez que a heterogeneidade dos resultados sintéticos entre conceitos e prognósticos (idéias, cooptações, artigos científicos, debates, discursos, obras escritas, manifestos, discussões, ensino, pesquisa, experimentos etc.) não pressupõe processo produtivo enquanto capital, embora a própria concorrência com os outros ramos ou dentro do próprio grupo possa levar, como a qualquer outro trabalhador, os indivíduos ao desemprego, mesmo salvaguardados da sorte do mercado.

É preciso, portanto, capturar essa massa humana por outros meios que não pelo processo produtivo, subsidiando as suas necessidades materiais às expensas do excedente do trabalho produtivo. Desta maneira, não há impedimento de qualquer um escolher o consumo de parte da mais-valia global para fins espirituais ou sutis, mas é preciso trilhar as vias normais necessárias estabelecidas pela sociedade. Na medida que esta escolha tenda para a determinação social, e esta tenda para aquela, é que haverá a possibilidade de concretização daquela "Justiça" de Platão, que "significa guardar apenas os bens que nos pertencem" e "exercer unicamente a função que nos é própria" (Platão, 1997: 133), seja na torre de marfim, seja na aridez do laboratório, seja no interior das massas.

\section{Condição 2: capacidade de otimizar racionalmente a atuação}

Quando um intelectual, no exercício de suas atribuições, organiza racionalmente a sua atuação, chega a um ponto no qual não pode mais melhorar essa sua atuação - seu limite somente é dado por outro intelectual ou, eventualmente, por ele mesmo, permanecendo dentro do grupo de intelectuais. Então, esse ponto racional é máximo ou ótimo. Esse ponto é crítico: durante o cami- 
nho há picos nos quais os conceitos e prognósticos estabelecidos demandam cada vez mais eficiência do pensamento, lógica interna e coerência, todos atributos da razão. Quando, dentre todos os pontos críticos dentro do grupo, há um em que se alcança o estatuto da inteligibilidade, a atuação somente pode piorar ou permanecer onde está.

Isso não significa, em grau algum, que o resultado da atuação, ou mesmo a contribuição do intelectual, necessariamente implique ciência, explicação correta do mundo, emancipação. Na maioria das vezes o produto é justamente o contrário e sua função pode ser mesmo a de pôr o mundo de cabeça para baixo, convencer pelo erro, cooptar, conservar a ordem. Afirmo apenas que esta construção não é irracional em si mesma: obedece a um estatuto de inteligibilidade ou de compreensão para o consumidor.

É exatamente disso que deriva a diferença entre o intelectual e o político: embora o político maximize a sua atuação, ele não o faz sempre racionalmente, porque há de decidir, e essa decisão em geral não resulta do conhecimento de princípios conforme a razão, e, até, é motivada inadvertidamente pela conjuntura, que enseja determinada tomada de decisão, ao passo que o intelectual, ao maximizar a sua atuação racionalmente, opera a todo instante sem o sacrifício da razão (4). Somente num momento a síntese operativa entre o intelectual e o político pode ser racionalmente máxima: no exercício da emancipação, da fusão entre teoria e práxis. Mas na política cotidiana, na política profissional (no sentido weberiano) é pouco provável. Para o político, e até para todas as demais atividades sociais, a razão há de estar inserta e dissolvida nos projetos que se concretizarão, na ética do trabalho para a minimização do desperdício e maximização do aproveitamento do tempo do operário, na organização dos meios pelos quais se dá o intercâmbio de informações, mas, para o intelectual, a razão sempre há de ter a primazia.

Portanto, nas formações sociais capitalistas, ao ser dada uma determinada tarefa própria do campo intelectual a um não-intelectual, não seria possível trilhar o caminho da eficiência: em cada ponto poder-se-ia obter melhorias, e isso prosseguiria sem um termo culminante. Ao contrário, a mesma tarefa atribuída a vários intelectuais resultaria, obviamente, em diferentes produtos, mas cada caminho haveria de alcançar o ponto racionalmente eficiente.

Com efeito, não é difícil encontrar um indivíduo que seja capaz de não otimizar racionalmente a sua atuação e, no entanto, ser um intelectual: muitos já tiveram a oportunidade de apreciar os guias regionais, no interior do Brasil, que apontam aos viajantes a geografia do lugar, o passado dos povoados, as idiossincrasias dos seus pares. Esse menu cultural, criado a partir de sua imaginação, decorado e, por que não, cantado, produz uma síntese conceitual daquele povoado, sem que tenha havido o uso eficiente da razão: cada vez mais, apesar da constância e repetição das mensagens, elas vão "melhorando", sendo 
agregadas de mais impressões pouco substantivas, embora apresentem-se muito convincentes, porque meramente descritivas: falta a explicação. $\mathrm{O}$ produto dele é claro e ataca o ensino racional da cultura regional nos recintos escolares do lugar. Não é, pois, necessário ao intelectual otimizar racionalmente a sua atuação.

\section{Condição 3: domínio substantivo do passado}

Em antológico texto, Lukács (1989: 19-20) coloca a importância do passado ao admitir os fatos como material imprescindível para o entendimento, embora se deva ter em conta quais informações devem ser relevantes para o conhecimento e, sobretudo, em que "contexto metodológico" (Idem: 19) isso se dará. No primeiro momento, de reconhecimento dos fatos, todos os intelectuais estão de acordo; mas no segundo, de modelação dos fatos, surgem todas os tipos de transtornos que hão de estabelecer as luzes, que iluminam ou que ofuscam. O essencial, portanto, é que a atividade intelectual há de se dar segundo aquele que domine substantivamente o passado, ou seja, com base no inventário de informações que deve ser apreendido, selecionado e processado dentro de um "contexto metodológico" (5).

O conhecimento substantivo do qual falo necessita de ambos os momentos. Embora não se possa falar do passado senão de maneira integral, pode-se admitir o passado enquanto categoria local: aquele que se dedicou a demonstrar "o último Teorema de Fermat" (Singh, 1999: 259) tinha plena autoridade acerca das condições a serem satisfeitas para empreender a prova, e essas condições obedeciam a várias outras colocadas à disposição, desde antes, para o mundo: o passado estava ali, também, e sob ele a história, embora seja ignorado na maioria das vezes. É com base nesta técnica que o intelectual colocará em relevo as parcelas do conceito e do prognóstico, de maneira fraca ou de maneira forte.

No desempenho de sua função ideológica, o intelectual fortalece os conceitos em detrimento dos prognósticos, pois dá prioridade ao que acha que é em detrimento do que acha que será, tentando alterar conceitos anteriores inculcados em seus interlocutores e dar-lhes os seus como verdadeiros. Tanto êxito terá quanto maior facilidade encontrar, por exemplo, pelo caminho aberto pelos aparelhos ideológicos colocados à disposição pelas instâncias de controle, favorecido pelas condições materiais de existência do ser. Desempenhando a função positiva de ciência, o intelectual fortalecerá os prognósticos em detrimento dos conceitos, pois não se trata mais de alterar outros conceitos, mas de colocá-los postos, com todo o autoritarismo universal, neste caso, próprio da ciência, que não dialoga sobre o erro do interlocutor: a hegemonia do conceito novo dissolve tudo que lhe for contrário e é imediatamente recebido, sendo os prognósticos a parcela forte, porque passível de dúvidas ou refutações. Por fim, no desempenho da função filosófica, as parcelas estão em equilíbrio dinâmico, tendo em vista as especificidades da filosofia, ou melhor, para 
falar como Sartre, das filosofias, uma vez que esta função fará uso do "filósofo", que é raro e que "lleva a la unificación de todos los conocimientos" (Sartre, 1963: 16); neste caso, o intelectual interage com a ciência e deriva as ideologias.

O contra-exemplo, que dá conta de não ser necessária qualquer expertise acerca do passado para ser um intelectual, quem o dá é Bobbio (1997: 114): "um operário que também desenvolva obra de propaganda sindical ou política pode ser considerado um intelectual", ainda que as informações, no caso da propaganda sindical, sejam pouco substantivas com relação ao passado e, sobretudo nos dias atuais, seja pouco certa a utilização de qualquer "contexto metodológico".

\section{A função do intelectual}

Com base nessa discussão, poder-se-ia concluir que se chegou a um impasse, pois, de acordo com os passos dados até aqui, a maior parte das pessoas que compõem a sociedade seria intelectual, e eu teria de concordar (6), uma vez que até o último parágrafo foi dada importância ao indivíduo, ao intelectual tomado isoladamente, e não ao campo de atuação, de maneira que seria fácil encontrar muitas pessoas que, de algum modo, tivessem de ser intelectuais para produzir algum resultado social: por exemplo, o "adivinhador" de chuva que, de tanto ter assimilado todas as condições empíricas que levam, com alta probabilidade, a um evento chuvoso, convence os interlocutores de seus dotes proféticos, mas não deixa de dar o prognóstico muitas vezes correto (7). Mas, na medida que se perguntem quais as condições para que o intelectual desempenhe a sua função, as três condições citadas agregadas a uma quarta fecham o campo, pois o indivíduo agregado à sua função há de resultar no que se convencionou chamar de intelligentsia (8), e se poderia dizer: um intelectual desempenha a sua função se, e somente se:

i. não repuser nem gerar valor;

ii. for capaz de otimizar racionalmente a sua atuação;

iii. dominar substantivamente o passado;

iv. sua ação estiver sendo mediada pela superestrutura com atribuições indelegáveis.

A superestrutura é constituída tanto pelas instituições da sociedade civil (9), que permitem a supremacia da classe dominante em toda a sociedade e que não têm ligação física com o Estado, exceto, eventualmente, enquanto receptoras de financiamento previsto em lei ou em acordo, quanto pelas instituições estatais propriamente ditas, que permitem o exercício da violência legal, instrumentalizando este domínio. Para que a função do intelectual se realize, é necessário e suficiente, além das três condições, a mediação dessas estruturas sem sua delegação a mais alguém. 
A produção intelectual tem, ao mesmo tempo, fins culturais, na medida que permite operar sobre e a partir da herança humana, altera o estado de consciência e ambiciona a revisão permanente das formas de conformismo, e tem fins artificiais, na medida que estipula o sentido da sociedade, cujo termo geralmente não é atingido, mas uma vez chegado o "momento histórico" fica mantido o consenso compulsório, devido aos mecanismos de violência legal.

Resulta dessa última condição o fato de os intelectuais, na realidade, comparados com os outros grupos, nada mais serem - como o são os operários empregados em uma fábrica - do que prestadores de serviço de seu próprio contexto, experts do passado, com capacidade racional ótima, sustentados pelas instituições. Desta maneira, os intelectuais não são uma casta, ou seja, para falar como Gramsci (1989: 11), “... este modo de colocar a questão entra em choque com preconceitos de casta; é verdade que a própria função organizativa da hegemonia social e do domínio estatal dá lugar a uma certa divisão do trabalho e, portanto, a toda uma gradação de qualificações...; mas, evidentemente, é preciso fazer esta distinção, como é preciso fazer também qualquer outra”.

Os intelectuais iluminam e definem o horizonte possível - e nenhum outro grupo, dadas as condições históricas que experimentam, de fecundo depositário do inventário social, poderia fazê-lo, ainda que por delegação -, segundo seja positiva ou negativa a função, que fundamentará o grau de aparência que se confundirá com a realidade percebida pelos consumidores dos seus produtos ou o grau de essência que será revelado, dado que o grau de consciência ou de falsa consciência atingido, de modo agregado, pelas classes da sociedade, não é cego mas determinado, embora a magnitude de cada contribuição, pública ou privada, dificilmente o seja.

Em outras palavras, se o intelectual exerce a função do seu campo, então as quatro condições foram realizadas e se as quatro condições forem realizadas para um intelectual, ele há de estar exercendo a função típica de seu campo. Mas qual a função do intelectual, ou melhor, para que é chamado? É preciso distinguir, neste momento, dentro de seu campo de atuação, a existência de dois, e apenas dois, tipos de intelectuais, cujo devir dos produtos difere radicalmente: o primeiro tipo é o intelectual negativo e o segundo tipo o intelectual positivo.

O intelectual positivo tem a tarefa de conceituar o sistema capitalista como aparentemente se apresenta e predizer a conversão do futuro em presente; o intelectual negativo tem a tarefa de conceituar a essência do sistema e predizer o futuro como superação do presente. Equivalentemente, o segundo tipo há de produzir conceitos nos quais somente se alcança o que o sistema efetivamente não é e prediz o futuro como já realizado pelas mesmas categorias do presente, consideradas intemporais, ao passo que o primeiro tipo produz conceitos nos quais o sistema é apresentado tal como ele é em sua totalidade e procura vaticinar o futuro com base na superação do que nega (10). 
A cisão irreconciliável entre os dois tipos de intelectuais com suas funções realiza-se exatamente naquela problemática central, e poucas vezes resolvida realmente na história, colocada pela XI Tese sobre Fenerbach (11), pois com o intelectual positivo a angústia reside sem dúvida alguma na forma pela qual se deve estar a um passo da transformação do mundo, e aí surge a questão da interação necessária entre teoria e práxis, a questão de o homem ser ao mesmo tempo sujeito e objeto da história e, com o intelectual negativo, a resolução é tranqüila ao entender que se trata simplesmente de interpretar o mundo de diferentes maneiras e não de transformá-lo, até porque, no limite, os incrementos das mudanças resultariam numa série convergente para o bem-estar.

Desta maneira, enquanto a intelligentsia negativa tenta investigar as formas pelas quais se deve fazer-se arma nas mãos daqueles que são o próprio devir histórico e sua resolução, ou ela mesma sê-lo, pois ainda não tem certeza, a intelligentsia positiva coloca-se como barreira intransponível para o devir entre as classes subalternas e as classes dominantes, inclusive operando a ciência como instrumento da conservação da ordem. Observe-se que não há maniqueísmo na distinção: um intelectual positivo pode perfeitamente estar a serviço da verdade, na medida que suas investigações, por exemplo, efetivamente contribuam para a solução de um problema relacionado com a origem do universo, mas esta verdade que ele persegue não se relaciona com a que perseguiria um intelectual negativo, para quem a atuação sempre deve resultar, não na verdade colocada como tal, mas no seu intercâmbio; não na verdade enquanto produto puro da ciência positiva, apta a ser alienada, mas enquanto história, enquanto totalidade.

\section{A caminho da obsolescência}

Em uma sociedade como a burguesa, na qual se coloca o imperativo de que é o espírito que determina o ser e na qual a ciência não é organicamente ligada à história, parece uma contradição admitir-se que a função do intelectual, que na maior parte dos casos reforça este imperativo e esta separação e que é chamada a todo o tempo para tanto, estaria em desuso: seria mais lógico, com base no triunfo da democracia burguesa sobre quase todo o globo, admitir-se, ao contrário, que cada vez mais estivesse sendo consolidada e gozando das liberdades que lhe devem ser tão naturais. E mais: deveria ser tanto mais necessária a sua "aparição" para fazer saber acerca das contradições do mundo burguês quanto de compor a coesão necessária entre as classes subalternas e a verdade a ser construída.

Se formos um pouco parcimoniosos em nossas considerações, verificaremos que a obsolescência das funções dos intelectuais não está relacionada com o seu "desaparecimento", "extinção" ou coisas que o valham: trata-se simplesmente de encontrar a constatação de que a função do intelectual não está sendo, como muito o foi, imprescindível, mas tornando-se cada vez mais dispensá- 
vel, devido, sobretudo, ao não atendimento das condições iii e iv retromencionadas. Há um predomínio grave na modernidade dos veículos transmissores sobre as técnicas demasiadamente "tradicionais" utilizadas pelos intelectuais. No primeiro caso, o cérebro pensa segundo uma programação estabelecida; no segundo, o cérebro pensa por si mesmo. O deslocamento é mais do agente predominante que é chamado pelas instâncias de controle: do homem para as coisas. Essa obsolescência não vem ocorrendo de forma abrupta, mas de maneira sutil ao longo dos últimos anos, após o apogeu da atuação do intelectual.

Pode-se resumir a evolução dessa atuação em três fases: ascensão, apogeu e declínio.

\section{Ascensão}

Toda classe que empreende a sua afirmação tem de se fazer por si mesma. No momento da consolidação de seu domínio, a classe burguesa haveria de estabelecer o modo pelo qual a sua Weltanschaunng teria de chegar às classes subjugadas. Com relação à classe oficial - a aristocracia derrubada -, haveria de herdar ou copiar a sua gens de lettre, traduzindo-a para a sua linguagem. Era preciso, então, penetrar neste mundo e colocar em utilização as estruturas superiores (12), às expensas da revolução industrial, perante as antigas: a profissionalização dos editores e dos jornalistas, com a aparição do jornal moderno, barato e difuso, foi a estrutura fundamental para a transmissão das idéias, e preservava de modo contundente o comportamento da gens de lettre e mesmo a educou, embora o uso do discurso falado, nos recintos públicos, nas praças e nos templos ainda fosse potencialmente mais útil no interior das massas, que não alcançavam educação superior.

Se a forma pela qual se colocavam os conceitos e os prognósticos havia de requerer do seu público alguma forma de instrução - embora houvesse uma certa cultura -, fazer chegar as mensagens pelas vias novas era pouco eficaz, dado o baixo grau de instrução e a superioridade dos próprios veículos transmissores porque, pelo menos até 1848, "mesmo nos países que adquiriram um sistema público de ensino, a educação primária era muito negligenciada; e, mesmo onde ela existisse, estava confinada, por razões políticas, a um mínimo de alfabetização, obediência moral e conhecimentos de aritmética" (Hobsbawm, 1989: 211-212) e quase totalmente voltada para aqueles que haviam de ser os homens instruídos ou de negócios. Neste momento, a estrutura capaz de coadjuvar a função do intelectual estava muito aquém de seu potencial, embora o mundo ainda fosse imenso e a urbanização estivesse apenas no seu começo.

Mais do que isso: era uma estrutura que não podia pensar por si mesma, e o crescimento da função do intelectual somente poderia estar sendo cada vez mais requerido pelas instâncias de controle. Pelo lado do intelectual negativo, as próprias condições de formação da classe ensejada pela burguesia - a proletá- 
ria - favoreciam a sua atividade, porque esta consciência - ainda que precária -, longe ainda da polêmica de ser ou não trazida do "exterior", tinha de ser colocada na ordem do dia pelo senso aguçado de uma população cada vez mais propensa à rebelião, pois se "a Revolução Francesa deu confiança a esta nova classe; a revolução industrial provocou nela uma necessidade de mobilização permanente", já que "uma existência decente não podia ser obtida simplesmente por meio de um protesto ocasional que servisse para restabelecer a estabilidade da sociedade perturbada temporariamente", de modo que "era necessária uma eterna vigilância, organização e atividade do 'movimento' - o sindicato, a sociedade cooperativa ou mútua, instituições trabalhistas, jornais, agitação" (Hobsbawm, 1989: 230), nos quais a função do intelectual encontraria, pela primeira vez, as possibilidades daquela realização da síntese entre palavra e ato.

Com relação à ciência, esta foi a época de construção das principais instituições no interior da superestrutura capazes de preparar o inventário científico burguês: os cientistas foram chamados pelos governos, a educação científica e tecnológica foi cercada pelos muros das universidades e das escolas politécnicas e as sociedades para o progresso da ciência foram fundadas: "a era revolucionária ... fez crescer o número de cientistas e eruditos e estendeu a ciência em todos os seus aspectos" (Hobsbawn, 1989: 304). Este extraordinário desenvolvimento científico ocorrido até 1848 iria se acentuar nos anos seguintes, servindo a todas as conquistas materiais requeridas pela indústria moderna, com base no rigor metodológico e na experimentação e utilização imediata da maquinaria. Ocuparia, enquanto idéia, já na década de 60 do século XIX, o lugar que sempre foi da filosofia, dando a mesma sensação que hoje temos do "fim" de certas coisas - por exemplo, fim das ideologias (13) - tal como nos conta Cournot apud Hobsbawm (1988: 261): “O fato de acreditar em verdades filosóficas saiu tanto de moda que nem o público nem nenhuma academia se dispõe a receber obras deste tipo, exceto como produto de puro academicismo ou curiosidade histórica".

Foi aí que se deu, para sempre, a colocação da função positiva da ciência como superior às outras duas, embora uma delas permanecesse ainda como tal - a função ideológica - e, não por acaso, houvesse, também aí, o último dos Filósofos - Marx -, embora surgissem muitos ideólogos (14). E superior por dois motivos: porque a sua realização deveria ser unilateral e se consumir principalmente nas mercadorias e porque a ciência não poderia, enquanto "contexto metodológico" no qual transita, jamais alcançar o primado perante a história, mas sujeitar-se a ela.

Mas de todas as instituições, enquanto estrutura apta a mediar a função do intelectual, deve-se sublinhar o surgimento e a proliferação dos partidos políticos, já no último quartel do século XIX, e com eles todas as engrenagens 
equacionadas na fórmula propaganda + voto em um sistema eleitoral cada vez mais universal: de um lado, como canais das demandas sociais até os dirigentes e que iriam fundamentar os grande pactos na metade do século XX; de outro lado, como bloco inevitável a partir do qual as contradições do sistema capitalista poderiam ser exibidas e, quiçá, superadas por outro sistema de produção. Nos movimentos inevitáveis de democratização, a partir de 1870, foi de importância, além de outros, o papel do intelectual no aperfeiçoamento da retórica e da demagogia que se iriam fazer presentes na boca do politician. A segunda onda democrática, como se diz, “... envolvia a organização de movimentos de massas e o desenvolvimento da mídia de massas - nesta fase, principalmente a recémdesenvolvida imprensa popular ou 'imprensa marrom"” (Hobsbawm, 1989: 130).

Era o momento da sociedade civil, com o desenvolvimento das estruturas próprias para a mediação dos interesses e do assentimento como os clubes, as associações de bairro, os sindicatos de abrangência nacional, mas também o momento do refinamento decisivo da consciência de classe e de formação dos novos príncipes em relação ao proletariado, que começava a ser "a grande maioria do povo" e única época na qual efetivamente "o proletariado ligava-se a seus partidos" organicamente: (Hobsbawn, 1989: 170-171) "É natural, aliás, que o extraordinário crescimento dos partidos socialistas e operários desde a década de 1880 haja infundido em seus membros e seguidores, bem como em seus líderes, um sentimento de exaltação, de esperança maravilhosa, da inevitabilidade histórica de seu triunfo. Jamais houvera época tão repleta de esperanças para aqueles que labutavam com as mãos, numa fábrica, numa oficina ou nas minas".

\section{Apogeu}

Se for possível eleger a época na qual os meios estavam à altura da função do intelectual, poder-se-ia indicar o período anterior à Primeira Guerra Mundial: de 1850 a 1913, nos países europeus mais adiantados, o analfabetismo caiu de cerca de 30\% para menos de 10\%; nos países europeus menos adiantados, e nos EUA reduziu-se substancialmente. Entre 1875 e 1913 as universidades surgiram na África, aumentaram em mais de um terço nos EUA e quadruplicaram-se na Ásia. O desequilíbrio mundial da informação mais popular espelhava-se no uso do papel de jornal, mostrando a supremacia da Europa, que concentrava cerca de $57,5 \%$ do seu uso, seguida da América do Norte, com 37\%, contra 5,5\% nos outros continentes (Hobsbawm, 1989: 474-475).

Mesmo as artes ainda requeriam os seus intelectuais, embora já estivesse em vias de aparecimento - com a penetração da tecnologia e a ampliação dos mercados com a globalização - a arte ma non troppo, que era uma concessão da erudição burguesa à ignorância das massas, que coexistiria e, até, iria interagir com a cultura popular tradicional: "ademais, a partir do fim do século XIX, o tradicional terreno da cultura erudita estava minado por um inimigo ainda mais poderoso: o fato de as artes atraírem as pessoas comuns (com exceção parcial da 
literatura) de terem sido revolucionadas pela combinação da tecnologia com a descoberta do mercado de massas. O cinema, a inovação mais extraordinária nessa área, juntamente com o jazz e seus vários descendentes, ainda não triunfara: mas em 1914 já estava muito presente e pronto para conquistar o mundo" (Hobsbawm, 1989: 308).

A função do intelectual estava, enfim, em seu apogeu. De certa forma, as estruturas existentes não poderiam sobreviver sem o cérebro da intelligentsia, ou seja, os meios não tinham autonomia alguma para eles mesmos atingirem os fins a que as instâncias de controle se propunham. O processo sintético entre os meios e a função do intelectual deveria dialogar com os consumidores, quando possível, de modo a penetrar em seu seio, estabelecer as idéias e mantê-las e não destruir o seu espírito. Quando comparada com nossa época, parece pouco eficiente esta sistemática da necessidade dos homens para o controle dos outros homens, mas os meios materiais disponíveis somente poderiam se ajustar ao que havia. Isso é fácil de observar com os rituais religiosos. Compare-se o doutrinamento moral e ético pelos pregadores desta época com os da atual, especialmente no Brasil urbano: na modernidade, não encontraremos jamais o intelectual em seu púlpito, mas um ator com seu scripte, na retaguarda, seu marketing. É engano imaginar-se, aqui, o doutrinamento religioso como argumento para o convencimento: a religião ficou no passado, está-se pregando diretamente o convencimento: uma religião ma non troppo.

Antes, era preciso certa dose intelectual dos próprios consumidores; hoje, esta etapa anterior já está tranqüilamente suprimida. Está porque, ao contrário do que se poderia pensar, não há mais aquela barreira cultural, profundamente histórica, que o mundo injusto tinha ainda de romper e que era a tarefa mais eminente e indelegável do intelectual. E, por mais paradoxal que pareça, a associação irreversível entre capitalismo e democracia é positivamente correlacionada com a destruição do passado enquanto estrutura filosófica e só esse mix poderia levar à perfeição a distribuição fascinantemente democrática dos produtos capazes de fazer sucumbir os homens (15).

Pelo lado da ciência, o período anterior à Primeira Guerra Mundial iria proceder ao expurgo definitivo de seus domínios de quaisquer intromissões filosóficas ou ideológicas, sobretudo de ordem religiosa. O seu escopo haveria de preocupar-se fundamentalmente com duas coisas: os procedimentos capazes de preparar, ainda que teoricamente, anteriore facto, a iminente explosão urbana e a limitação de seus produtos, o mais imediatamente possível, aos fins do capital, cabendo o seu inventário apenas aos iniciados porque, como diria Lênin, melhor poucos mas bons, o que é muito válido em ciência: "Daqui em diante a ciência tornou-se não apenas algo que poucas pessoas podiam entender, mas também algo de que muitos discordavam, embora crescentemente reconhecessem sua dependência em relação a ela" (Hobsbawm, 1989: 345). 
Não havia mais os homens da aurora capitalista que, quando não sabiam, inventavam; hoje, somente são levados a sério pelas instituições oficiais de patente: os recursos materiais, para serem operados, necessitariam cada vez mais da ciência antes, daí a introdução, nas próprias empresas, dos laboratórios e, quando não no próprio espaço industrial, o financiamento dos cérebros nas fundações públicas ou privadas.

\section{Declínio}

Contudo, a partir do interregno entre as duas guerras mundiais, haveria de ser iniciada a proliferação de novos meios que não apenas pudessem penetrar mais rapidamente em uma população mundial que não era "capaz" de educar-se de modo formal (16) - ou seja, pelas letras - mas apenas aproveitar-se de seus sentidos visuais e auditivos de maneira mais passiva do que a trágica barreira da leitura: "as forças que dominaram as artes populares foram assim basicamente tecnológicas e industriais: imprensa, câmara, cinema, disco e rádio" (Hobsbawm, 1985: 196) e fundação da nova diversão ou entretenimento, de maneira que as estruturas disponíveis começaram a ficar mais autônomas do que seus próprios intelectuais, que deveriam fazê-las pensar.

É a constituição da indústria cultural, veementemente atacada por Adorno e Horkheimer. Nenhum outro intelectual, como eles dois, se preocupou tão obsessivamente em descrever o que não estava mais sendo executado pelo intelectual, embora historicamente fosse de sua atribuição, isto é, imputar aos homens uma cosmovisão com base em alguma pedagogia. Com suas características peculiares de ramificação a partir do ambiente urbano e de sua idealização, facilidade na distribuição em série do produto cultural standard dentro de um próprio procedimento standard, a indústria cultural conseguiria triunfar sobre o espirito antes de qualquer reflexão e recrutaria sobretudo pequeno-burgueses e o proletariado industrial de melhor renda aos seus esquemas: "Os consumidores são os trabalhadores e os empregados, os lavradores e os pequenos burgueses. A produção capitalista os mantém tão bem presos em corpo e alma que eles sucumbem mais facilmente ao que lhes é oferecido. Assim como os dominados sempre levaram mais a sério do que os dominadores a moral que deles recebiam, hoje em dia as massas logradas sucumbem mais facilmente ao mito do sucesso do que os bem-sucedidos. Elas têm os desejos deles. Obstinadamente, insistem na ideologia que as escraviza. O amor funesto do povo pelo mal que a ele se faz chega a se antecipar à astúcia das instâncias de controle (Adorno \& Horkheimer, 1994: 125).

Em resumo: a indústria cultural, como meio, já começando a se tornar independente da função do intelectual propriamente dita, não apenas subjugou o seu objeto atendendo à "demanda de porcarias", descaracterizando ou neutralizando o "inventário cultural", prometendo mas não cumprindo os seus desígnios e reprimindo mais do que sublimando (Adorno \& Horkheimer, 1994: 
125-126, 130-131), mas também induzindo a dependência permanente aos seus produtos, talvez o seu objetivo crucial (17).

Perante o que ainda viria, já no final deste século, ou seja, o fato de que o homem poderá não mais ser o futuro do homem, somente um espírito otimista como o do Sartre de 1946, 25 anos antes de curvar-se, ao seu modo, a Marx (18), poderia conceder uma ideologia - o existencialismo - da escolha perpetuamente factível: “O existencialismo não pensará nunca, também, que o homem pode conseguir o auxílio de um sinal qualquer que o oriente no mundo, pois considera que é o próprio homem quem decifra o sinal como bem o entende. Pensa, portanto, que o homem, sem apoio e sem ajuda, está condenado a inventar o homem a cada instante" (Sartre, 1987: 9).

Se a função filosófica já havia, há muito, se tornado obsoleta, mas mantendo uma atividade residual devido à presença permanente do último filósofo, a partir daí a função ideológica é que iria conhecer a sua pouca praticidade, embora a função positiva de ciência mantivesse, como se viu, a sua supremacia na função do intelectual, o que é compreensível: desde o início da organização das sociedades fundadas na exploração havia de ser a filosofia e, quase pari passu, a ideologia os primeiros desenvolvimentos maciços em torno da racionalidade e do entendimento. A ciência positiva é incomparavelmente mais nova, enxerga a natureza não como um obstáculo com o qual deve se resignar mas como algo que deve ser cada vez mais subjugado aos seus caprichos e não somente sepultou - com o seu método - as concepções metafísicas, demasiado aristotélicas, fracamente rigorosas e sem lógica interna do passado "científico" mas também, como explica Weber apud Aron com relação às ciências, "sua tarefa se defronta com a fragilidade de todas as construções (19) ideal-típicas, mas são inevitavelmente obrigadas a elaborar continuamente outras... Nenhum desses sistemas de pensamento, que não podemos desprezar se quisermos apreender os elementos cada vez mais significativos da realidade, pode esgotar sua riqueza infinita" (Aron, 1995: 533).

Em outras palavras, há duas exigências relacionadas com a ciência positiva. Uma é endógena: por ela ser o futuro de si mesma, há de sempre requerer, em princípio, a mediação humana; a segunda é exógena: por ela ser chamada sistematicamente antes da concepção de um dado processo produtivo, a função há de ser sempre usada. Não duvido, entretanto, de que possa chegar, no interior do capitalismo, a era de estacionamento desta função: não do fim da ciência, como não se fala do fim da filosofia ou da ideologia, mas no desuso da função do intelectual que a empreenda.

Como se viu, até meados dos anos 50, exceto onde a indústria cultural não podia substancialmente penetrar, isto é, nas populações do campo que mais tarde seriam expulsas para as cidades, nas camadas mais deterioradas da sociedade, nos guetos miseráveis, nas camadas subempregadas e no próprio 
proletariado dos países satélites, aliás, um contingente populacional considerável (20), seguramente ainda era relativamente firme a necessidade da função do intelectual, porque operava fundamentalmente mediante os meios tradicionais e o passado permanecia agregado à barreira cultural.

Se, por um lado, não restava dúvida que a ampliação do saber com base na educação formal não estava na agenda efetiva da maioria dos Estados e, para reforçar o problema, a penetração dos produtos dos intelectuais somente podia fazer-se por meios tradicionais, por outro lado era preciso buscar alternativas mais eficientes que superassem esse caminho demasiado sofisticado de interagir com os consumidores. Por sua vez, devido a diferentes razões, a função intelectual negativa já estava mesmo condenada a ser ignorada ou mesmo banida do mundo capitalista após, sobretudo, a ruína da URSS e do Leste Europeu (21). A contribuição primeiro da televisão, depois da programação, que subentende uma espécie de reforma da superestrutura, e, finalmente, dos esquemas destruidores do passado, seria algo decisivo. E se a ambição de A. Smith jamais se concretizara onde devia - isto é, no mercado -, mesmo antes da forte intervenção do Estado após a paz de 1945, pelo menos poderia se regozijar vendo-a nos mecanismos de controle social onde a mão invisípel coordenaria a oferta e a procura dos produtos ideológicos até o ótimo social, produtos esses cujo processo de fabricação, hoje, apenas imita a produção ampliada das mercadorias, que “... consiste em que as capacidades intelectuais do homem são ampliadas e inclusive substituídas por autômatos, que eliminam com êxito crescente o trabalho na produção e nos serviços" (Schaff, s/d.: 22).

A questão da homogeneidade cultural - a partir da qual se inicia a supressão ou dissolução das culturas locais, ligadas ao passado - vem à tona, de início, com a transferência paulatina da produção de estúdio "público" para a produção de estúdio "privado", a partir de 1960, por meio da televisão (22). As massas poderiam ser alcançadas cada vez mais universalmente (23), uma vez que atrás da televisão viriam a vulgarização do uso da energia elétrica, o fetichismo das mercadorias, o contínuo barateamento dos aparelhos, a revolução nos meios de comunicações e a compactação de um menu de entretenimento sempre disponível, mas apenas idealizável, facilmente consumível.

Se bem que, já nos anos 90, a televisão não fosse ainda capaz de por si mesma idiotizar, pelo menos já tinha a vantagem de aperfeiçoar os que se ajudassem nesta empresa, devido às suas condições materiais, aliás, a grande maioria: o menu de alternativas é ao mesmo tempo fechado à opção tanto mais proporcionalmente a renda diminua (24). É que quando o contingente subalterno vai aumentando passa a se tornar mais rigorosa a captura e reduzidas as escolhas, porque o confronto entre as culturas é desvantajoso. Nesta interação, quem inicia o jogo é a televisão, selecionando o seu público de acordo com a sua mentalidade. Note-se que o menu é variável, mas o público escolbido por 
cada programa é mais ou menos fixo. A função intelectual é desempenhada pela própria televisão enquanto meio: o próprio aparelho é capaz de manipular os fatos e processá-los em um contexto metodológico uniforme e repetitivo, a exemplo dos telejornais, das telenovelas, dos programas infanto-juvenis e dos programas que divulgam a vida privada, crimes e acidentes (25), nos quais a contribuição para o ritual pode ser dada por qualquer um que satisfaça os requisitos tayloristas: tomar para si as tarefas mecânicas e desempenhar as regras estabelecidas por quem desempenha as tarefas intelectuais - no caso, o próprio meio -, o que é uma inversão contundente (26).

Da forma como é preparada - como função intelectual autônoma -, a televisão não deve ser entendida apenas como um serviço participante da divisão da mais-valia, voltada para a divulgação do que se encontra no mercado, mas como algo que é um importante instrumento de distribuição justa dos produtos inúteis, mas capazes de tolher o que resta de inocência no indivíduo, de chamar à ética e de imputar a repressão, inclusive sexual. É a substituição, afinal, da arte pela técnica levada ao seu paroxismo: técnica que se pensa, que é tão eficiente quanto mais não admita aquelas propriedades inerentes às artes das quais nos fala Walter Benjamin (27): a autenticidade, que trás um testemunho histórico, a aura, que descreve os elementos espaciais e temporais do objeto, sem desencantá-lo, em sua imagem original e a função social.

Com efeito, a televisão é apenas um aspecto - daí resultam o fato de se ter de investigar mais profundamente o seu alcance e a desconfiança, com a qual eu concordo, de que ela teria baixa capacidade de implementar isoladamente a resignação, embora a encontrando a aperfeiçoe - de uma mudança muito mais profunda que vem tendo lugar nos últimos anos, especialmente a partir da crise dos Estados, consistente na incapacidade de manter os pactos sociais do passado, na iminente insustentabilidade de seus sistemas de previdência e de seguridade social e nas demandas cada vez mais heterogêneas e incapazes de serem atendidas em meio à permanente contradição entre os interesses nacionais e a intensificação da volatilidade autônoma da mais-valia em todo o globo na forma de capital financeiro. Era preciso encontrar novos mecanismos de controle (28), que preservassem o mix capitalismo/democracia, mas mais eficientes do que a onerosa reciprocidade entre a sociedade civil e o Estado. Não a busca do "Estado mínimo" - o relatório do Banco Mundial (1997) diz o bastante acerca da inseparável dependência do capitalismo com relação ao Estado -, mas a delegação cada vez maior à sociedade civil de muitas atividades, inclusive a do seu próprio controle.

De certa forma, isso não tem precedentes porque, até há algumas décadas, sempre foi suprema a presença do Estado na superestrutura - e ainda o é enquanto financiador e responsável. O momento da sociedade civil já se dera há muito tempo, como já mencionado. Trata-se agora de ela começar a empreen- 
der, com o considerável auxílio e supervisão do Estado, o seu autoconstrangimento (29). É por isso que esta reforma na superestrutura afasta a função do intelectual e introduz a função intelectual nos próprios meios, deslocando o agente (do homem para as coisas): a eficiência consiste em encontrar meios adequados que, uma vez inicialmente programados, possivelmente por intelectuais, empreendam de maneira autônoma a função que, um dia, fora do homem (30). Só aí poder-se-á tomar stricto sensu a situação segundo a qual, no capitalismo, o homem é realmente um ser social, em que se há de alcançar o trágico estado circular: o homem é feito, faz e torna a ser feito.

A sociedade civil, ao controlar-se a si mesma, dispensa, naturalmente, qualquer expertise, porque ela própria, aí, é a superação de suas amarras em torno dos transtornos do passado. Não há necessidade de se conhecer os dados coligidos e nem de processá-los em um universo metodológico - portanto, não há necessidade de conhecimentos substanciais acerca do passado, porque tudo isso já está circunscrito a uma lógica pré-estabelecida, capaz de readaptar-se a qualquer momento, desde que se lhe reprograme as determinações. O papel da informática nisso, portanto, é essencial. E esta última será tanto mais frutífera quanto mais diminua as distâncias, encurte o tempo, perpetue o presente e consiga prever as idiossincrasias do seu objeto.

Assim é que a ciência positiva não vem tendo apenas o papel de instrumentadora da produção, ela também vem se tornando indispensável para solucionar problemas com a forma pela qual o autoconstrangimento da sociedade deve se dar de modo eficiente. É por isso que ela deve preparar meios de comunicação e de informação ad hoc. Torna-se a função positiva de ciência, também, soberana perante as duas outras funções intelectuais e mesmo universal - não enquanto verdade ou divulgação, mas enquanto instrumentadora do processo de radicalização das relações sociais. Sem a ciência, os meios autônomos da função ideológica não seriam muita coisa, hoje.

A presença das relações sociais (31) tem de ser total (32), de maneira que a liberdade de cada um possa ser predita e aquele intervalo do "possível" - lembrando Sartre - seja cada vez mais suficientemente modulado de forma a que inviabilize qualquer efeito agregado. Isso significa que aquelas esferas da ação humana, até mesmo os mais triviais comportamentos ou as mais comezinhas atitudes, nas quais se poderia excluir o determinante social, e se aplicar, em última instância, outras explicações a-históricas (política, psicológica, psicanalítica, psiquiátrica, acidental, econométrica etc.) começam a ficar cada vez mais reduzidas e tudo paulatinamente se vai concretizando segundo o furor da história (as famosas e, para muitos, detestáveis condições materiais): um policial que assassina aparentemente de modo banal um inocente, um estudante que extermina toda a sua classe em um dia ao acaso, uma mulher que em um momento qualquer expõe sua vida privada a mais de 30 milhões de telespectadores 
de modo grotesco etc. A grande desvantagem para a classe dominante - e, por outro ângulo, a saída - desse aperfeiçoamento do domínio social é o fato de que, na verdade, o efeito agregado, embora evitado e tornado cada vez mais difícil - mudar o mundo, como disse Hobsbawm alhures, é muito mais difícil hoje do que antigamente -, uma vez iniciado é explosivo e irreversível, porque vai encontrar as próprias relações sociais nos limites de sua tensão com as forças produtivas.

Note-se que o Estado, com suas instituições e seus intelectuais, não está se retirando de sua fundamental atuação ideológica. Ao contrário, até o exercício da violência se torna cada vez mais eficiente, com a reforma da burocracia, a penetração cada vez mais contundente das estruturas físicas de contenção (presídios, organismos jurisdicionais, isolamento dos guetos e dos redutos da parte carcomida da estrutura social) nos locais mais críticos, a antecipação às explosões cívicas com base na ridicularização pública de suas plataformas; a própria estrutura política permanece, apesar do comportamento peculiar da política atualmente (33), como os parlamentos e as estruturas ad hoc dos pleitos. No entanto, muitas de suas tarefas estão sendo cada vez mais postas à livre concorrência no interior da sociedade civil (partidos políticos, organizações não governamentais, organizações sociais, fundações de direito privado, imprensa, televisão etc.), coadjuvada diretamente pela estrutura produtiva e seus resultados (comércio e serviços): quem oferecer este produto social sui generis - altamente inelástico - ao menor custo tem maior probabilidade de "vender" mais. O importante é elevar todos os atos ao supremo dominio privado, a desagregação humana - não a extinção do relacionamento com o outro ou de qualquer relacionamento social, mas a efetivação destes na medida que esta interação seja banal e a-cultural. Nada cria raízes, exceto travestido de opções (Sousa Santos, 1997: 103-124).

Finalmente, cabe discutir o último dos três pontos listados, que são os esquemas destruidores do passado. Essa é, acima de qualquer outra razão que possa vir reforçar a presença da barbárie, a constatação fundamental: o corte radical entre presente e passado e a manutenção de seu esquecimento. Ainda que estudado, é negligenciado mais adiante. E não apenas o passado coletivo está sendo sepultado, mas o próprio passado mundano, de cada um. Ora, uma geração que não se ressente em não herdar, como todas as outras o fizeram, os escombros produzidos pela geração anterior e não se incomoda em não assumir o peso da ilusão e do conformismo anteriores não pode ir muito longe: "A destruição do passado - ou melhor, dos mecanismos sociais que vinculam nossa experiência pessoal à das gerações passadas - é um dos fenômenos mais característicos e lúgubres do final do século XX. Quase todos os jovens de hoje crescem numa espécie de presente contínuo, sem qualquer relação orgânica com o passado público da época em que vivem" (Hobsbawm, 1995: 13). 
A gravidade da recusa em manter-se um link com a geração anterior distorce ou danifica a força de invocação do passado, que sempre deve ser efetivada quando se pretende empresar os acontecimentos futuros. E não há de ser gratuito esse sacrifício da história, porque o preço é o sepultamento da própria humanidade. O mundo não começa a sua própria ruína apenas com a deterioração dos seus meios materiais - algo improvável -, mas com a ignorância a respeito do "sopro do ar que foi respirado antes" (Benjamin, 1987: 223) e que condicionou toda a operação sobre esses meios materiais.

De um lado, há de se salientar o fato de que o sacrifício do passado - empresado por todas as classes -, que faz capitular até os mortos (Benjamin, 1987: 224-225), é um empreendimento relativamente consciente das classes dominantes e, quanto a isto, nada está fazendo senão afirmar a sua tarefa: manter o mundo interpretado tal qual havia fundado na sua aurora, não obstante revolucionando incessantemente os meios de produção; de outro lado, com relação às classes subalternas, deve-se sublinhar a sua reprodutibilidade histórica, e cuja desorganização não pode ser desculpada pelo fato de estar cooptada e inconsciente do quanto está deixando de cumprir no que se refere ao seu imperativo histórico. É uma obrigação histórica dupla, o último vestígio, talvez, do Angelus Novus - em primeiro lugar, é ética a obrigação, porque não há quem possa redimir a humanidade senão aquela classe que, solucionando os seus problemas, solucione o de toda a sociedade; é, finalmente, necessária a obrigação, porque a história estará condenada a reproduzir a irregularidade se não for $\mathrm{o}$ proletariado quem assuma as rédeas da sua gênese. O homem não pode continuar fazendo-se homem com base na operação dos fatos com contexto metodológico artificial, sem a mediação do homem.

Na realidade, não se está criticando - e seria inócua a tentativa - o fato de a novidade dissolver a tradição, verdadeira ou inventada, com ou sem diálogo, para a assunção do progresso. Isso sempre a burguesia o fez. Nem mesmo se está perseguindo a rejeição in totum da substituição contínua do fazer antigo pelo fazer novo. Tudo isso é per se salutar - Marx salientou várias vezes a importância, inclusive no Manifesto do Partido Comunista, da herança para o proletariado de todo o arsenal tecnológico, científico e de informações se este triunfar. $\mathrm{O}$ problema é que o modus operandi não permite tempo para o registro do tempo anterior, o arquivamento da tradição destruída, o reconhecimento do que se tornou obsoleto; a novidade - reacionária - que substitui a tradição - reacionária - não capta a diferença na sua memória porque aqueles que chegam a ignoram ou não a reconhecem. Ou seja, o problema não é o produto mesmo, mas o subproduto resultante do processo. Não se deseja uma rememoração objetiva do passado para reconstruí-lo, mas o passado enquanto inventário e parâmetro de comparação (referencial). O passado como experiência efetivamente realizada: aprender não somente com erros, mas com acertos. "Mas se o futuro parece vazio de sentido, o passado está tão indisponível como sempre. A capacidade 
de fulguração, de irrupção, de explosão, de revelação, em suma, a capacidade messiânica (...) foi conferida ao futuro pela modernidade ocidental. A incapacitação do futuro não abre qualquer espaço para a capacitação do passado. Pura e simplesmente, deixamos de saber olhar o passado de modo capacitante" (Sousa Santos, 1997:105).

\section{Conclusão}

A tendência da dispensa da função do intelectual, que neste artigo tentou-se mostrar, não é senão um resultado das leis singulares da sociedade capitalista, como quaisquer outros resultados já mostrados por estudiosos ao se falar neste contumaz produtor de barbáries. Evidentemente, a sua incapacidade de retroagir, de recuperar perdas é praticamente nula, já que não pode se libertar de suas contradições, e nem se espera que a resolução delas, e a fortiori de todos os seus efeitos, seja dada por qualquer reforma, pois, neste caso, vai ter de pressupor e assentar-se nas mesmas leis. Não é possível predizer a saída, mas parece que simplesmente o discurso e a divulgação dos efeitos não é, em grau algum, suficiente para alertar, até porque aqueles aos quais cabe transformar o mundo estão cada vez mais inalcançáveis.

Se a natureza desse ao homem, antes de nascer, a opção de vir à luz no primeiro, no segundo ou no terceiro terço do século, certamente eu escolheria o final do primeiro terço, porque ninguém há de me convencer de que a probabilidade de vislumbrar a esperança que Zeus soltou da caixa de Pandora junto com as desgraças do mundo é máxima em fin-de-siècle. Mas o que é aparentemente fatal pode guardar algo de bom também, porque somente numa época de ilusão - no mau sentido - extrema poder-se-ia pensar na dignidade da libertação cujo alcance não está em outro lugar senão na resolução de nosso próprio tempo, no empreendimento tão antigo quanto igualmente inatingível até hoje e, possivelmente, cada vez mais, consistente no modo pelo qual se deve realizar aquele princípio primeiro, em virtude do qual tudo é feito, colocado por Aristóteles, à sua maneira, na Ética a Nicômaco: "a felicidade", a qual "pressupõe não somente existência perfeita, mas também uma existência completa" (Aristóteles, 1996: 130).

Notas

1 Os intelectuais são bem anteriores ao capitalismo. Como escreve Bobbio (1997: 1011), fazendo uma auto-reflexão, "o erro [acerca da extinção dos intelectuais] depende também do caráter restrito, nesse caso não de natureza lógica [falsa generalização], mas de origem histórica, com que é usada a categoria dos intelectuais, como se ela não tivesse sempre existido, embora com outros nomes, e como se ela só tivesse nascido quando, no final do século XIX, com o affaire Dreyfus, difundiu-se 
o uso da palavra, primeiro na França e depois em todo o mundo civilizado". Concordando com o fato de que não se trata, nem este texto irá declarar isso em nenhum momento, de extinção dos intelectuais, acentuo, porém, o fato de que cada forma produtiva social permitiu a esta clique tanto o que deviam ser quanto o que efetivamente foram ou fizeram - daí minha restrição às sociedades atuais, no caso, a burguesa.

2 É desnecessário dizer que mesmo o erário, do qual flui o pagamento dos recursos humanos recrutados pelo Estado, o subsídio e os repasses às organizações da sociedade civil, é provido pela mais-valia tributável em última instância e que aparece aos nossos olhos na forma monetária dos impostos. Isso em termos preponderantes, excluindo-se uma parte menor, referente à tributação direta sobre o próprio "valor" da força de trabalho (salário dos trabalhadores que efetivamente acrescem valor ao produto). Na verdade, quanto à arrecadação estatal ou à arrecadação supervisionada pelo Estado, como a filantropia, o mecenato e os incentivos privados, trata-se de retirada momentânea de parte da mais-valia circulante, realizada em dinheiro e, quanto à primeira arrecadação, compulsória (tributos), visa ao entesouramento (lastro) e manutenção da máquina estatal. Não penetrarei detalhes técnicos ou rigorosos da matéria, que podem ser inferidos de Marx (1991).

3 A propósito, já Marx, ele mesmo o último dos Filósofos, a respeito de uma passagem do Leviatã, na qual o autor dessa obra lamenta o pouco caso para com a ciência em relação às riquezas materiais, consolava T. Hobbes escrevendo que "o produto do trabalho intelectual - a ciência - está sempre abaixo do valor" e explicava-lhe "que o tempo de trabalho necessário para reproduzi-la não guarda em absoluto proporção alguma com o tempo de trabalho requerido pela produção original" e que "um colegial, por exemplo, pode aprender em uma hora o teorema do binômio" (Marx, 1987: 339).

4 Prescreve Bobbio (1997: 82) que “...a tarefa do intelectual é a de agitar idéias, levantar problemas, elaborar programas ou apenas teorias gerais; a tarefa do político é a de tomar decisões".

5 Como se viu no item anterior, infere-se que o ótimo racional pode, por assim dizer, assemelhar-se - e o é muitas vezes - ao ápice daquilo a que Aristóteles disse ser tarefa do sábio: ordenar. Note-se que é um ordenamento ideal, mas raramente um ordenamento de facto, pois isso depende, afinal de contas, também do domínio sobre as coisas, especialmente do passado e, conseqüentemente, dos métodos. Não significa que o domínio seja apenas o exato (no sentido do materialismo histórico), ou que inclua, também, o passado corriqueiro e mundano. A realidade do modo de produção capitalista, por exemplo, é exemplarmente desordenada, irregular e caótica, e somente com a aplicação do método, constante da Contribuição à crítica da economia política, de Marx, é que ganha o estatuto de concreto pensado, método esse rejeitado por boa parte dos sábios.

6 Segundo Gramsci (1989: 6-7), a distinção entre os intelectuais e os outros agrupamentos não reside nos indivíduos, mas na função desempenhada. Escreve ele: "o erro metodológico mais difundido ... consiste em se ter buscado este critério de 
distinção no que é intrínseco às atividades intelectuais, ao invés de buscá-lo no conjunto do sistema de relações no qual estas atividades ... se encontram, no conjunto geral das relações sociais" Desse modo, "todos os homens são intelectuais ...; mas nem todos os homens desempenham na sociedade a função de intelectuais" (Idem: 7). E acrescenta - nos dias atuais, soando demasiado otimista - que fora do exercício da atividade econômica, a razão e o fazer são indissociáveis, donde se abre alguma atividade intelectual: "todo homem, fora de sua profissão, desenvolve uma atividade intelectual qualquer, ou seja, é um 'filósofo', um artista, um homem de gosto, participa de uma concepção do mundo, possui uma linha consciente de conduta moral, contribui assim para manter ou para modificar uma concepção do mundo, isto é, para promover novas maneiras de pensar" (Idem: 7-8).

7 Embora não tenha otimizado racionalmente a sua atuação, uma vez que tem muito a melhorar, ao passo que o produto gerado por um físico, no caso o modelo de predição computacional, é o limite de sua atuação racional - mas não de todas as pesquisas, frise-se bem - e é capaz, inclusive, de indicar a banda de confiança dentro da qual está o valor esperado da resposta, e possa errar mais do que o "adivinhador".

8 Doravante, por simplicidade, confundo o homem - intelectual - ou o grupo - intelectuais - com sua função.

9 Adoto o conceito gramsciano e não marxiano, pelo menos em parte, pois para Marx, talvez pela confusão na tradução da expressão alemã bürgerliche Gesellschaft, sociedade civil é "la organización social que se desarrolla directamente basándose en la producción y el intercambio, y que forma en todas las épocas la base del Estado y de toda otra supraestructura idealista" (Marx \& Engel, 1968: 38), ou seja, o Estado é a expressão da sociedade civil antes definida e não entidades complementares e recíprocas que formam a superestrutura como em Gramsci (1989:10-11). Em linha semelhante à de Gramsci, segue Althusser (1985, p. 69), segundo o qual há um "Aparelho (repressivo) do Estado, unificado, pertencente inteiramente ao domínio público" (que, aqui, chamo, simplesmente, de instituições estatais) e os "Aparelhos Ideológicos do Estado", como as "igrejas, os partidos, os sindicatos, as famílias, algumas escolas, a maioria dos jornais, as empresas culturais etc.", os quais remetem "ao domínio privado" (que chamo, aqui, de instituições da sociedade civil, simplesmente), sendo a diferença básica entre os dois termos que aquele "funciona através da violência", enquanto estes "através da ideologia" embora, como salienta, aqueles, também, façam uso da ideologia e estes da violência, cada um em grau mais atenuado.

10 Há um preconceito, dentro e fora do rendez-vous, a respeito do estabelecimento de predições. Deve-se esclarecer contra esta ingenuidade que o fato de explicar implica, ainda que implicitamente, predizer em uma ordem social fundada na irregularidade; não há interpretação sem conceitos e prognósticos neste caso. Somente em uma ordem social fundada na regulação, e somente nela, a predição em geral perde importância, exceto em ciências exatas - nas quais o controle sobre a natureza é crítico: por exemplo, a predição, com base em um modelo estocástico, de uma enchente com dado período de retorno -, porque o futuro haveria de ser aproximadamente o que se planejou no presente. 
11 "Los filósofos se han limitado a interpretar el mundo de distintos modos; de lo que se trata es de transformarlo" (Marx \& Engels, 1968: 668).

12 "O efeito da revolução industrial sobre a estrutura da sociedade burguesa foi superficialmente menos drástico, mas na verdade bem mais profundo, pois criou novos blocs burgueses que coexistiam com a sociedade oficial, muito grandes para serem absorvidos por ela, exceto por uma pequena assimilação no topo, e muito autoconfiantes e dinâmicos para desejar uma absorção, exceto em seus próprios termos" (Hobsbawm, 1989: 206).

13 De modo simplificado, as ideologias existem - e sempre existirão em sociedades fundadas na irregularidade - porque o diferencial entre essência e aparência, entre realidade e representação sempre vai ser produzido e distribuído com o fim de controlar as expectativas, orientar o objetivo da ação agregada dos indivíduos e presidir o grau de consentimento individual (conformismo), permitindo, no caso da sua função positiva, a estabilidade das relações sociais como algo natural, ou melhor, pelo menos na sociedade capitalista, a ocultação das contradições sempre auto-reveladas em flash, e preservando o domínio universal. O que aqui se discute fundamentalmente com relação a elas é que está havendo, desde a metade do século $\mathrm{XX}$, um progresso coerente com a própria produção capitalista, no sentido de cada vez mais conferir autonomia aos meios, tornando obsoleta a mediação do homem, no caso a função do intelectual, e não o declínio das ideologias.

$14 \mathrm{E}$ destes, os escritores de literatura foram mais numerosos do que os exegetas dos grandes mortos.

15 E se Marx, para explicar a razão pela qual "certas épocas do florescimento artístico" ainda nos causam prazer artístico, mesmo que deslocadas de sua base material, como a mitologia, indagara-se "quem é ... Hermes em comparação com o Crédito Mobiliário?” (Marx, 1983: 228), poderia, hoje, na mesma linha, indagar-se: o que é o Crédito Mobiliário perante os mecanismos que ensejam o desencanto, por exemplo, pela "infância histórica da humanidade" ? (Idem: 229).

16 Sobretudo no Terceiro Mundo, onde "só uma minúscula camada possuía o necessário conhecimento, educação ou mesmo alfabetização elementar" (Hobsbawm, 1995: 201).

17 É bem verdade, no entanto, que Adorno tinha apenas uma pequena amostra para generalizar a verdadeira universalização da indústria cultural e pouca idéia da faixa de renda dos consumidores de seus produtos, especialmente em torno de 1945, como é o caso do cinema, exemplo com o qual era maior a sua má vontade: "seu esquema geral de abordagem do cinema pode ser visto como uma operação de sinédoque, aquela figura retórica na qual se toma a parte pelo todo. A meu ver, Adorno teria tomado "... a parte hollywoodiana do cinema para seu todo" (Silva, M., 1999: 114-126). Prova disso foram os movimentos cinematográficos posteriores à década de 50 empreendidos por tantos homens de bom gosto em sua função ideológica.

18 Em Questão de método, que prefacia a Crítica da razão dialética, de 1960. 
19 Embora ela seja, paradoxalmente, a meu ver, o mais rebuscado dos idealismos.

20 Sem muitas mudanças até os dias atuais, pois "se tomamos os membros dos países ricos da OCDE como representando o 'mundo desenvolvido', sua população coletiva no fim da década de 1980 representava uns meros 15\% da humanidade" (Hobsbawm, 1995: 338).

21 Exceto, talvez, em insulamentos de alguns partidos políticos e nas academias, e assim mesmo no seio dos professores, onde se encontra refugiada. E se a história nunca propunha a Lênin, que a considerava ardilosa, perguntar-lhe o que ele já havia respondido, o faz hoje: "Que Fazer?".

22 Escolhi a televisão apenas por simplificação, porque a mesma análise é, mutatis mutantis, extensiva a todos os meios ou mídias semelhantes, tanto os já citados (por exemplo, cinema, rádio, revistas) quanto toda a sorte de show pirotécnico ou não, a produção sonora, as exibições públicas de curiosidades reprodutíveis, mensagens disponíveis na internet etc. Especialmente com relação à internet, ver os resultados, que deverão ser divulgados no endereço http://www.institutoagora.org, do pioneiro seminário Brasil-Reino Unido na Sociedade da Informação, realizado em Curitiba, no período de 26 a 28 de novembro de 2001, no qual se discutiu a relação entre a cidadania e uma suposta sociedade da informação.

23 “A televisão jamais se tornou tão prontamente portátil quanto o rádio ..., mas domesticou a imagem em movimento. (...) Na década de 1980, cerca de $80 \%$ de um país como o Brasil tinha acesso à televisão. Nos países avançados, começou ... a levar toda a gama de imagem filmada à telinha doméstica” (Hobsbawn, 1995: 484).

$24 \mathrm{E}$ a fidelidade também. Fidelidade não à televisão mesma ou a um único canal, mas a algum de seus programas, o que é muito mais importante.

25 “O proletariado é capaz de seduzir-se com o seu próprio estado: por exemplo, um acidente (como uma enchente, um desabamento etc.) que nos é informado pela TV: o miserável conforta-se com sua própria efetividade e, com alguns ajustes do grupo de controle, a tragédia se lhe torna apetecível" (Santos, Roberval, 1995: 18).

26 É por isso que as chamadas televisões culturais, vinculadas ao Estado e que vão desaparecer, não têm autonomia intelectual: a função intelectual é fortemente dependente de cérebros humanos e há uma interação mais harmoniosa entre a cultura oferecida e a que a assiste: é clara a ineficiência perante a televisão convencional, sobretudo ao se considerar o tempo necessário ao convencimento e os vários instrumentos de mediação, dentre os quais a suposição de um background anterior por parte dos telespectadores. O procedimento é o tradicional, pedagógico, de rompimento das barreiras, até porque o público que recorre a ela é certamente mais "sofisticado".

27 Ver Benjamin (1987: 170). É bem verdade que este autor tinha esperanças acerca do destino emancipatório das artes tecnicamente reprodutíveis (cinema, rádio, fotografia, imprensa etc., e seu subproduto, a televisão), em trechos célebres: a vulgarização da função intelectual: "com a ampliação gigantesca da imprensa (...) a diferença essencial entre autor e público está a ponto de desaparecer" (Idem: 184), a 
realidade seria menos contemplação e mais revelação: “a descrição cinematográfica da realidade é para o homem moderno infinitamente mais significativa que a pictórica, porque ela lhe oferece o que temos o direito de exigir da arte: um aspecto da realidade livre de qualquer manipulação pelos aparelhos, precisamente graças ao procedimento de penetrar, com os aparelhos, no âmago da realidade" (Idem: 187). Infelizmente ele não sobreviveu para ver o quanto este destino não se cumpriu.

28 Essa busca incessante de saídas, nas sociedades burguesas, deriva de uma singularidade desse modo de produção com relação aos anteriores, que se traduz em uma famosa proposição marxista. Como sempre escrevendo com muita propriedade, Lukács (1989: 35) a enuncia: "só no terreno do capitalismo, da sociedade burguesa, é possível reconhecer na sociedade a realidade".

29 Neste sentido é que se poderia admitir, hoje, que não apenas o Estado, de modo legítimo, exerce o "controle do conflito de classe no âmbito de um quadro estável de instituições e valores, pairando ostensivamente acima e fora delas, ... e ao assim fazer perpetua uma sociedade que de outro modo seria esfacelada por suas tensões internas" (Hobsbawm, 1998:167), mas também os próprios organismos civis privados estão tendo uma considerável participação neste controle, induzindo a família e, até, o próprio indivíduo a aprender a conter a si mesmo.

30 Um exemplo singular da absorção da função intelectual pelo meio, substituindo a função do intelectual, são os autômatos falantes, aventados por Shaff ao descrever a sociedade que não vem vindo tal como ele havia predito, "que transmitem conhecimentos em diversos campos e estão programados a estabelecerem um 'diálogo' com o estudante, fazendo-lhe perguntas e corrigindo as respostas equivocadas" (Schaff, s/d.: 72).

31 Obviamente, as relações sociais de produção sempre estão atuantes e se pretendem universais no capitalismo. Aqui, porém, refiro-me à sua manifestação ou aparição, que há de requerer certa superestrutura, onde residem os instrumentos científicos, ideológicos e filosóficos e os instrumentos de violência e que se torna continuamente total.

32 À primeira vista, parece a descrição do totalitarismo. Ao contrário, supondo um continuum entre o mix capitalismo/totalitarismo e o mix capitalismo/democracia, deste estão ausentes várias características presentes naquele: a fusão entre sociedade civil e Estado; a dissolução da esfera privada pela hegemonia radical da esfera pública; o terror como instrumento; a mentira como instituição da imputação da vontade exorbitante do déspota; o Estado não apenas monopoliza a violência, como também toda e qualquer operação acerca das representações, sendo ele mesmo o seu meio e a burocracia o executor exclusivo. Ver a respeito o interessante trabalho de Lefort (s/d.: 7-55).

33 "A política, embora seja uma atividade ainda necessária para a lógica superestrutural capitalista, é feita por uma multidão de homens perplexos no final das empreitadas, quando as determinações exógenas ao processo caem sobre suas cabeças, ou apáticos perante a convocação para a resolução de problemas domésticos" (Santos, Roberval, 1998: 89-101). 
Referências bibliográficas

ADORNO, Theodor \& HORKHEIMER, M. Dialética do esclarecimento. Rio de Janeiro, Zahar, 1994.

ALTHUSSER, Louis. Aparelhos ideológicos de Estado. Rio de Janeiro, Graal, 1985.

ARISTÓTELES. Ética e Nicômaco. São Paulo, Nova Cultural, 1996.

ARON, Raymond. As etapas do pensamento sociológico. São Paulo, Martins Fontes, 1995.

BANCO MUNDIAL. Relatório sobre o Desenvolvimento Mundial. Washington, Banco Mundial, 1997.

BENJAMIN, Walter. Obras escolhidas, v. 1. São Paulo, Brasiliense, 1987.

BOBBIO, Norberto. Os Intelectuais e o Poder. São Paulo, UNESP, 1997.

GRAMSCI, Antonio. Os intelectuais e a organização da cultura. Rio de Janeiro, Civilização Brasileira, 1989.

HOBSBAWM, Eric. A era do capital. Rio de Janeiro, Paz e Terra, 1988.

HOBSBAWM, Eric. A era dos impérios. Rio de Janeiro, Paz e Terra, 1989. - A era das revoluções. Rio de Janeiro, Paz e Terra, 1989. A era dos extremos. São Paulo, Companhia das Letras, 1995. Sobre história. São Paulo, Companhia das Letras, 1998.

LEFORT, Claude. Esboço de uma gênese da ideologia nas sociedades modernas. Estudos CEBRAP. São Paulo, CEBRAP, n. 10, p. 7-55, s/d.

LUKÁCS, Georg. História e consciência de classe. Rio de Janeiro, Elfos, 1989.

MARX, Karl. Contribuição à crítica da economia política. São Paulo, Martins Fontes, 1983.

v.1. Teorias da Mais-valia. Rio de Janeiro, Bertrand Brasil, 1987, 1.4, O capital. Rio de Janeiro, Bertrand Brasil, 1991, 1.2, v.III.

MARX, Carlos \& ENGELS, Federico. La ideología alemana. Montevideo, Pueblos Unidos, 1968.

PLATÃO. A República. São Paulo, Nova Cultural, 1997.

SANTOS, Roberval. Rudimentos de dialética. Não-publicado, 1995.

Cento e cinqüenta anos do manifesto do partido comunista: para enterrar os grandes mortos. Anos 90. Porto Alegre, UFRGS, n. 10, p. 89-101, 1988.

SARTRE, Jean Paul. Critica de la razón dialéctica, t. 1, 1. 1. Buenos Aires, Losada, 1963. 
SARTRE, Jean Paul. O existencialismo é um humanismo. São Paulo, Nova Cultural, 1987.

SCHAFF, Adam. A sociedade informática. São Paulo, Brasiliense, s/d.

SILVA, Mateus. Adorno e o cinema: um início de conversa. Novos Estudos, São Paulo, CEBRAP, n. 54, p.114-126, 1999.

SINGH, Simon. O último teorema de Fermat. Rio de Janeiro, Record, 1999.

SOUSA SANTOS, Boaventura. A queda do Angelus Novus. Novos Estudos. São Paulo, CEBRAP, n. 47, p. 103-124, 1997.

RESUMO - Neste artigo discute-se a evolução da função do intelectual nas sociedades capitalistas e apresentam-se as condições necessárias e suficientes para o desempenho da função. A partir do não-atendimento a algumas dessas condições, o autor mostra a tendência de um futuro no qual esta função essencialmente humana deixará de ser imprescindível.

ABSTRACT - In this paper is discussed the evolution of the function of the intellectual in the capitalist societies and are showed the necessary and sufficient conditions for the function performance. Starting from the non attendance of some of those conditions, the author shows the tend of a future in which this essentially human function will stop being indispensable.

Roberval de Jesus Leone dos Santos é mestre pela Universidade Federal do Rio Grande do Sul (UFRGS). Formado pela Escola Nacional de Administração Pública (ENAP), é integrante da carreira de Especialista em Políticas Públicas e Gestão Governamental do Ministério do Planejamento, Orçamento e Gestão. E-mail: jleone@zipmail.com.br.

O autor agradece as inúmeras sugestões de Nilson A. Carvalho Figueiredo Filho, integrante da mesma carreira. 